\title{
MIT APP INVERTOR PADA APLIKASI SCORE BOARD UNTUK PERTANDINGAN OLAHRAGA BERBASIS ANDROID
}

\author{
Muhammad Najib Dwi Satria' ${ }^{1)}$, Fajar Saputra ${ }^{2)}$, Donaya Pasha ${ }^{3)}$ \\ ${ }^{1,3}$ Sistem Informasi, Universitas Teknokrat Indonesia \\ ${ }^{2}$ Informatika, Universitas Teknokrat Indonesia \\ 1,2,3 Jl. H.ZA Pagaralam, No 9-11, Labuhanratu,Bandarlampung

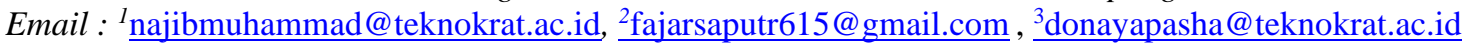

\begin{abstract}
Current technological developments seen from several perspectives of life underwent many changes and also made it easier for human work to do their daily work. One example is an android smartphone which has various features that vary according to needs. In sports for example, many match systems make use of technology that makes it easy for the scorer to determine the winner and helps to manage the assessment by remote control using a smartphone in real time. The match system between branches is certainly different, both in terms of scoring and match time. Therefore the authors build an Android-based application that is integrated with the score board that is used to facilitate the referee to determine the match scores in several sports. Because it is known that each sport has different regulations regarding the scoring system and its time. This research is intended to produce an aplication score board the using matrix P1O LED that can be controlled via smartphone with the android platform. The score board application that will be made later can be used in several sports such as futsal, basketball, veleyball and badminton.
\end{abstract}

Key words: Score Board, Smartphone Android, P10 LED Matrix, Arduino Uno, Bluetooth.

\begin{abstract}
Abstrak
Perkembangan teknologi saat ini dilihat dari beberapa persepektif kehidupan mengalami banyak perubahan dan juga mempermudah pekerjaan manusia untuk melakukan tugasnya sehari-hari. Salah satu contoh yaitu smartphone android dimana memiliki berbagai fitur yang beraneka ragam sesuai dengan kebutuhan. Dalam olahraga misalnya, sistem pertandingan banyak yang memanfaatkan teknologi yang mempermudah juru nilai untuk menentukan pemenang dan membantu untuk mengatur penilaian dengan cara dikendalikan jarak jauh menggunakan smartphone secara real time. Setiap cabang pertandingan tentunya memiliki system yang berbedabeda, baik dalam segi penilaian maupun waktu pertandingan. Maka dari itu penulis membangun aplikasi berbasis android yang terintregasi dengan papan skor yang digunakan guna mempermudah juru nilai untuk menentukan hasil pertandingan pada beberapa cabang olahraga. Seperti setiap cabang olahraga pastinya memiliki suatu aturan yang berbeda tentang sistem penilaian dan juga waktunya. Penelitian ini dimaksudkan adalah untuk menghasilkan suatu aplikasi score board dengan menggunakan matrix p10 LED yang bisa dikontrol melalui smartphone dengan platform android. Aplikasi score board yang akan dibuat nantinya dapat diaplikasikan pada beberapa cabang olahraga seperti voli, futsal, basket, voli dan bulutangkis.
\end{abstract}

Kata kunci: Score Board, Smartphone Android, P10 LED Matrix, Arduino Uno, Bluetooth.

\section{Pendahuluan}

Olahraga saat ini berkembang seiring dengan kemajuan teknologi di era modern saat ini. Banyak pertandingan-pertandingan yang menggunakan alat pendukung yang serba canggih dan otomatis. Berbagai cabang pertandingan olahraga yang di pertandingkan sebagai contoh yaitu, futsal, basket, bulu tangkis dan bola voli.

Adapun beberapa sistem yang masih ditemukan belum mendukung sistem penilaian yang dilihat masih tergolong manual. Dengan adanya aplikasi ini nantinya diharapkan sistem pada pertandingan dapat memanfaatkan teknologi yang mempermudah penilaian wasit untuk menentukan pemenang dan juga mempermudah panitia untuk mengatur skor dengan dikendalikan jarak jauh menggunakan smartphone secara real time. Sistem pada pertandingan olahraga tentunya berbeda-beda, dilihat dari segi penilaian maupun waktu pertandingan. Dengan adanya aplikasi ini maka diharapkan dapat membantu dan bisa mempermudah dalam beberapa cabang olahraga. 


\section{Landasan Teori}

Pada bagian ini akan membahas mengenai teori dasar yang melandasi penelitan sebagai bahan acuan dalam melaksanakan penelitian

\section{Arduino}

Arduino merupakan sebuah mikro single-board yang dapat dikendalikan dengan open-source. platform ini dirancang untuk memudahkan penggunaan dalam berbagai bidang. Pada prossesor Atmel AVR atau Atmel ARM memiliki software bahasa pemrogramannya sendiri[1].

Platform pada Arduino sebagai komputer pisik yang bersifat open source. Platform Arduino tidak hanya sekedar sebuah alat pengembangan, tetapi juga bisa sebagai suatu kombinasi dari Integrated Development Environment (IDE), hardware, dan bahasa pemrograman dan yang canggih[2]. Ada beberapa projek yang dikembangkan oleh kalangan akademisi maupun profesional dengan memanfaatkan Arduino dan terdapat juga banyak modul-modul pendukung seperti sensor, tampilan, penggerak dan sebagainya untuk bisa disambungkan dengan Arduino. Banyak praktisi yang menggunakan platform ini untuk dijadikan sebuah acuan dalam penelitian atau pemanfaatan teknologi.

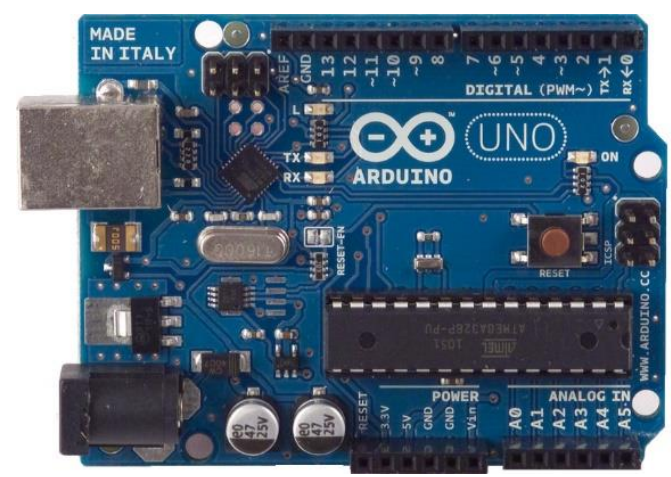

Gambar 1. Arduino Uno

Arduino Uno dilihat pada gambar 1 Arduino UNO adalah sebuah board mikrokontroler yang didasarkan pada ATmega328. Dalam bahasa italian "Uno" berarti satu dan dinamai untuk menandakan keluaran (produk) Arduino 1.0. Arduino UNO merupakan seri terakhir dari sebuah board Arduino USB dan papan Arduino untuk model refrensinya. Arduino Uno berbeda dari semua board Arduino sebelumnya, dimana tidak menggunakan chip driver FTDI USB-to-serial. Sebaliknya, fitur-fitur Atmega16U2 diprogram sebagai sebuah pengubah USB ke serial. Revisi ke dua dari board Arduino Uno memiliki sebuah resistor yang menarik garis 8U2 HWB ke ground dan membuatnya lebih mudah untuk diletakkan ke dalam DFU mode.

\section{Bluetooth}

Bluetooth merupakan alat atau protokol komunikasi wireless yang bekerja pada frekuensi radio $2.4 \mathrm{GHz}$ dengan tujuan untuk pertukaran data pada perangkat bergerak seperti HP, PDA ataupun laptop[3]. Pada modul Bluetooth HC-05 ada 6 pin konektor, yang dimana setiap pin konektor memiliki fungsi yang berbeda - beda. Untuk gambar module bluetooth dapat dilihat pada gambar 2 .

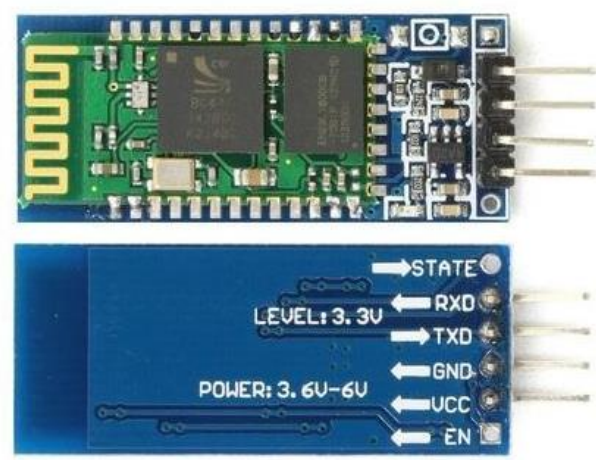

Gambar 2. Modul Bluetooth HC-05

HC-05 dengan supply tegangan sebesar 3,3V kepin12 sebagai VCC. Pada modul bluetooth Pin 1 sebagai transmitter dan receiver pada pin 2. Modul pada bluetooth HC-05 bisa menjadi slave ataupun master dan dapat dibuktikan dengan memberikan notifikasi untuk melakukan pairing pada perangkat lain. Untuk mengatur perangkat pada bluetooth dibutuhkan suatu perintah AT Command dan akan di respon oleh perangkat bluetooth jika tidak dalam keadaan terkoneksi dengan perangkat lain.

\section{P10 LED Matrix}

LED adalah sebuah komponen elektronik yang dapat memancarkan cahaya monokromatik ketika diberikan tegangan maju. Bahan semikonduktor pada LED merupakan keluarga dari Dioda. LED memancarkan warna cahaya dan tergantung pada jenis bahan semikonduktor yang digunakannya[4].

LED terdiri dari sebuah chip semikonduktor dengan proses doping dalam semikonduktor untuk menambahkan ketidakmurnian (impurity) pada semikonduktor yang murni sehingga menghasilkan karakteristik kelistrikan yang diinginkan. Ketika LED dialiri bias forward yaitu dari Anoda (P) menuju Katoda (K), jika kebihan Elektron pada NType material akan berpindah ke wilayah yang bermuatan positif (P-Type material). Saat Elektron berjumpa dengan Hole maka akan melepaskan photon dan memancarkan suatu cahaya monokromatik (satu warna). 


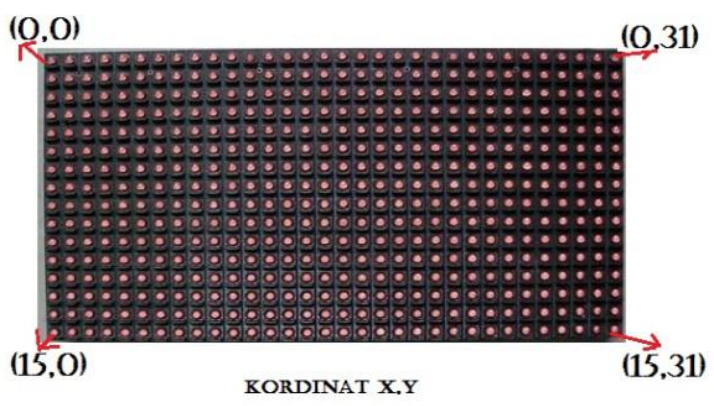

Gambar 3. P10 LED Matrix

Panel P10 LED Matrix adalah sebuah panel LED yang memilikiukuran $16 \times 32$ dengan jumlah LED sebanyak 512 biji per panel nya[5]. Jarak antara masing masing LED adalah $10 \mathrm{~mm}$ yang merupakan LED super bright yang akan sangat jelas dilihat saat siang hari. Panel ini merupakan panel dengan tipe semi outdoor, yang artinya akan tahan jika diletakkan diluar ruangan. Namun tidak tahan terhadap air dari sisi depan panel karena tidak dilapisi oleh silikon yang dapat mencegah masuknya air ke rangkaian PCB seperti panel full outdoor .

\section{MIT AppInvertor}

MIT AppInventor merupakan aplikasi inovatif yang dikembangkan oleh Google dan MIT dengan tujuan mengenalkan dan mengembangkan pemrograman daripada sebuah android dengan mentrasformasikan bahasa pemrograman yang kompleks berbasis teks menjadi berbasis visual (drag and drop) berbentuk blok-blok.

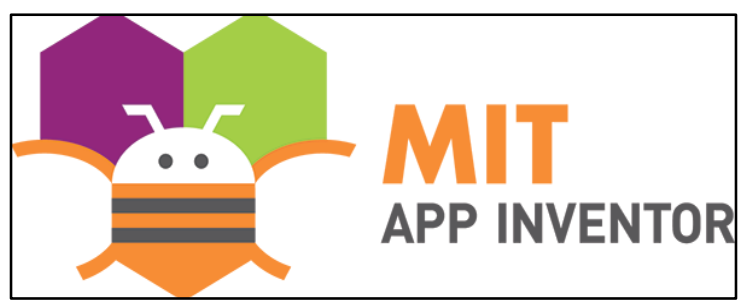

Gambar 4. Logo MIT App Invertor

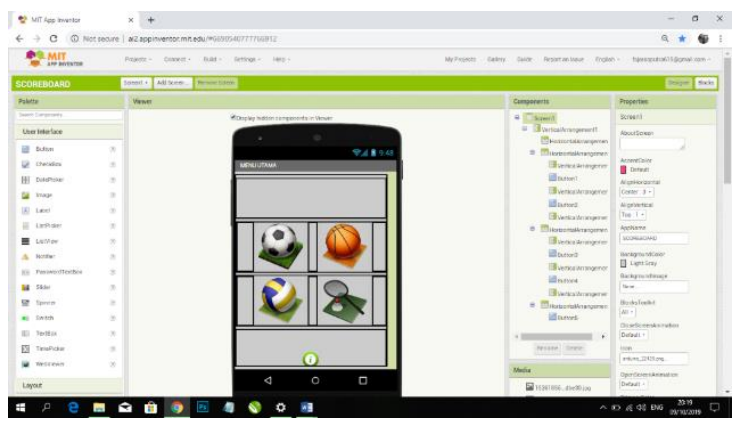

Gambar 5. Tampilan MIT App Invertor

App Inventor adalah aplikasi web sumber terbuka yang dikembangkan oleh Google dimana saat ini dikelola oleh Massachusetts Institute of Technology
[6]. App Inventor memungkinkan pengguna baru dapat memprogram suatu komputer agar dapat membuat aplikasi suatu perangkat lunak untuk sistem operasi pada platform android. App Inventor juga menggunakan tampilan antarmuka grafis yang serupa dengan antarmuka pengguna pada Scratch maupun StarLogo TNG untuk men- drag-and-drop suatu objek visual dalam menciptakan aplikasi yang dapat beroperasi pada perangkat Android.

\section{Sistem Penskoran}

Dalam setiap pertandingan olahraga olahraga diperlukan suatu sistem penilaian untuk mengetahui hasil dari pertandingan tersebut. Tentunya dengan tujuan agar dapat menentukan pemenangnya. Ada beberapa cabang olahraga yang menggunakan sistem penilaian diantaranya futsal, basket, dan lain sebagainya.

\section{Futsal}

Sistem penilaian pada olahraga futsal apabila bola masuk kegawang lawan terhitung +1 dengan durasi pertandingan yaitu $2 \times 20$ menit. Dan ada juga yang menggunakan waktu $2 \times 15$ menit atau $2 \times 10$ menit. Jika dalam waktu tersebut kondisi pertandingan seimbang maka akan diadakan pertandingan tambahan (extra time) $2 \times 5$ menit. Dan Jika masih seimbang, maka akan diadakan pinalti. Peraturan pada futsal sama seperti pada olahraga sepakbola yang membedakan hanyalah waktu, jumlah pemain dan lebar lapangan.

\section{Basket}

Olahraga basket memiliki sistem penilaian bernilai $+1,+2$ dan +3 dilihat dari jangakuan eksekusi/pelemparan bola yang masuk ke ring lawan. Pada permianan bola basket dimainkan dalam waktu $4 \times 10$ menit dalam 4 babak dan tiap babak memiliki durasi waktu 10 menit.

\section{Bulu Tangkis}

Pada olahraga bulu tangkis system penilaiannya yaitu +1 untuk setiap bola (shuttle cock) yang jatuh pada daerah lawan. Jika salah satu tim lawan mendapat point 11 maka akan diadakan perpindahan tempat dan istirahat. Pemain atau tim yang menang yaitu yang mendapatkan poin 22 dalam 3 ronde. Pemain atau tim yang menang dalam 2 ronde sekaligus dinyatakan pemenang dalam pertandingan tersebut.

\section{Voli}

Sistem penilaian dalam olahraga voli sistem penilaiannya sama dengan bulu tangkis. 


\section{Metode Penelitian}

Dalam penelitian perancangan score board menggunakan kendali smartphone android ini menggunakan jenis penelitian kuantitatif yang artinya metodologi yang berdasarkan data dari hasil pengukuran berdasarkan variabel penelitian yang ada. Pada suatu pertandingan sistem penilaian dilakukan menggunakan aplikasi yang telah dirancang pada platform android. Dengan berbasis bahasa pemrograman java dan xml. kemudian software eclipse sebagai softwarenya.

\begin{tabular}{|c|c|c|}
\hline APK \\
ANDROID
\end{tabular}$\longrightarrow \begin{gathered}\text { Bluetooth } \\
\text { HC-05 }\end{gathered} \longrightarrow \begin{gathered}\text { Micro Controler } \\
\text { Arduino Mega 2560 }\end{gathered} \longrightarrow \begin{gathered}\text { LED RGB } \\
\text { (Nilai) }\end{gathered}$

Gambar 6. Blok Diagram Perancangan Sistem

\section{Alat Dan Bahan}

Tabel 1. Alat Dan Bahan

\begin{tabular}{|c|c|c|c|}
\hline No & $\begin{array}{c}\text { Alat dan } \\
\text { Bahan }\end{array}$ & Ukuran & Keterangan \\
\hline 1. & $\begin{array}{l}\text { P10 LED } \\
\text { Matrix }\end{array}$ & 3 Unit & $\begin{array}{l}\text { Digunakan } \\
\text { sebagai tampilan } \\
\text { skor } \\
\text { pertandingan. }\end{array}$ \\
\hline 2. & $\begin{array}{l}\text { Arduino } \\
\text { Uno R3 }\end{array}$ & 1 Unit & $\begin{array}{l}\text { Dipergunakan } \\
\text { sebagai } \\
\text { penyimpan data } \\
\text { yang telah } \\
\text { diprogram. }\end{array}$ \\
\hline 3. & $\begin{array}{c}\text { DMD } \\
\text { Konektor }\end{array}$ & 1 Unit & $\begin{array}{l}\text { Dipergunakan } \\
\text { untuk } \\
\text { menyambungkan } \\
\text { kabel dari led ke } \\
\text { mikrokontroler } \\
\text { arduino }\end{array}$ \\
\hline 4. & $\begin{array}{l}\text { Bluetooth } \\
\text { HC-05 }\end{array}$ & 1 unit & $\begin{array}{l}\text { Digunakan } \\
\text { sebagai } \\
\text { penghubung } \\
\text { koneksi dari } \\
\text { smartphone ke } \\
\text { led }\end{array}$ \\
\hline 5. & $\begin{array}{l}\text { Kabel } \\
\text { Jumper }\end{array}$ & 4 unit & $\begin{array}{l}\text { Digunakan } \\
\text { untuk penghu- } \\
\text { bung slot dari } \\
\text { Bluetooth ke } \\
\text { mikrokontroler } \\
\text { arduino }\end{array}$ \\
\hline 6. & $\begin{array}{c}\text { Adaptor } \\
\text { TP-Link } \\
9 \mathrm{v}\end{array}$ & 1 unit & $\begin{array}{l}\text { Dipergunakan } \\
\text { sebagai adaptor } \\
\text { untuk } \\
\text { menghubungkan } \\
\text { ke listrik }\end{array}$ \\
\hline
\end{tabular}

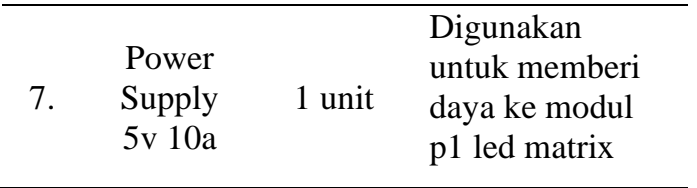

\section{Konsep Perancangan}

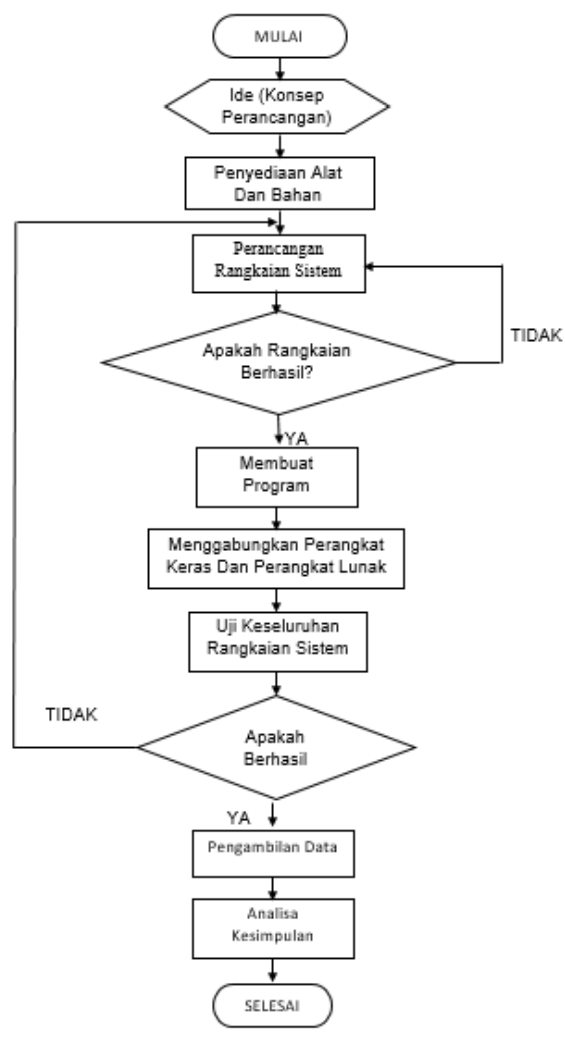

Gambar 7. Diagram Alir Konsep Perancangan

Pembuatan score board ini dimulai dengan perancangan mekanik sehingga membentuk arsitektur yang diinginkan. Kemudian dilakukan perancangan elektrik berupa wiring antara system IO nya. Selanjutnya dilakukan proses programming yaitu pembuatan aplikasi android menggunakan eclipse software dan pembuatan logika mikrokontroler menggunakan Arduino software. 


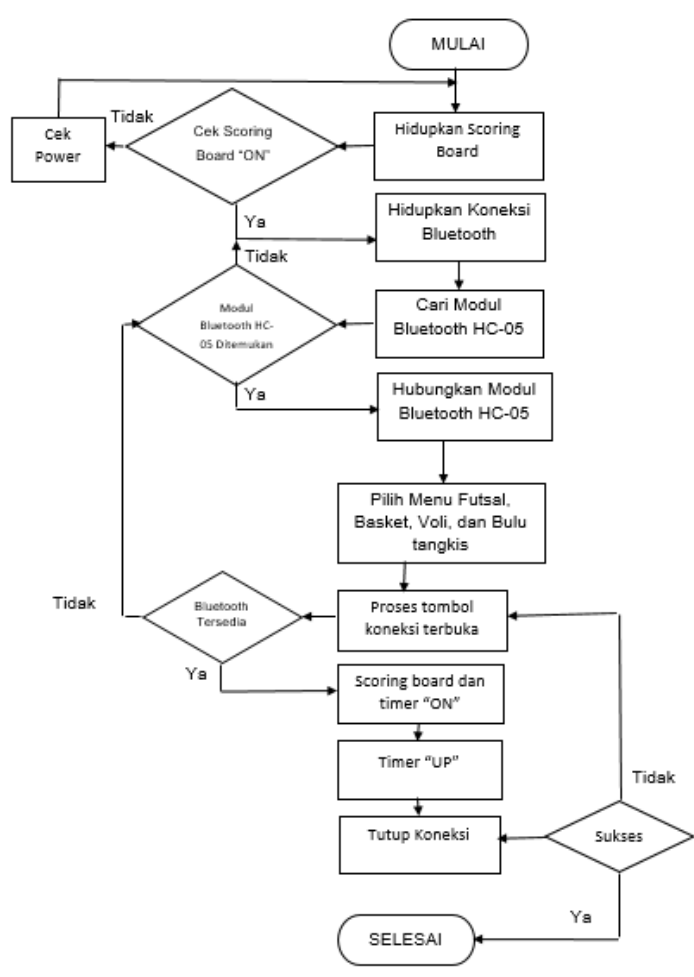

Gambar 8. Diagram Alir Perancangan Sistem

Melihat dari diagram alir diatas bahwa peran modul Bluetooth HC-05 berperan untuk menjalankan program baik dari sisi pemrograman eclipse. Dengan adanya modul Bluetooth HC- 05 ini koneksi antara Arduino dan eclipse dapat berjalan dengan baik.

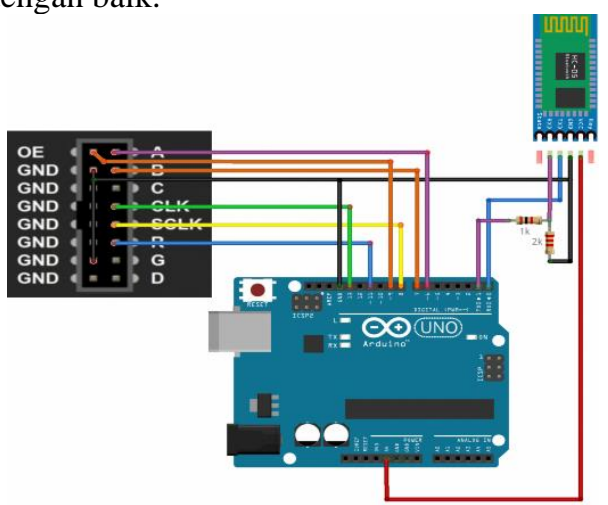

Gambar 9. Skema Alur Arduino Uno, Bluetooth dan P10 LED Matrix

\section{Hasil dan Pembahasan}

Proses dalam membangun aplikasi dan alat score board mengunakan MIT App Invertor dan berbasis Mikrokontroler Arduino mencakup perancangan, persiapan komponen, pembuatan, pemasangan komponen dan pengujian kerja. Sistematika prosesproses tersebut. Hasil produk merupakan barometer keberhasilan dalam pembuatan produk. Hal tersebut dapat dilihat dari kualitas fisik produk dan kinerja saat diuji. Pembahasan merupakan ulasan dari proses pembuatan, perancangan dan pengujian yang telah dilakukan.

Hasil rancang bangun sistem secara keseluruhan adalah mencakup pada perangkat mekanika, elektronika dan program komputer. Rancang bangun sistem ini apakah yang dibuat telah dapat memenuhi tujuan yang hendak dicapai dan memberikan sedikit analisa sistem kerjanya. Sedangkan pengujian rangkaian elekrtonika yang dibuat dan pengujian program komputer akan dilakukan terhadap program yang telah dibuat.

\section{Hasil Rancang Bangun Keseluruhan}

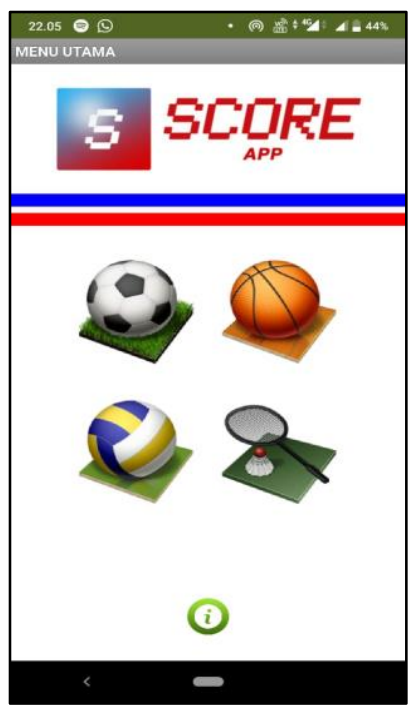

Gambar 10. Tampilan Menu Utama Aplikasi Score Board

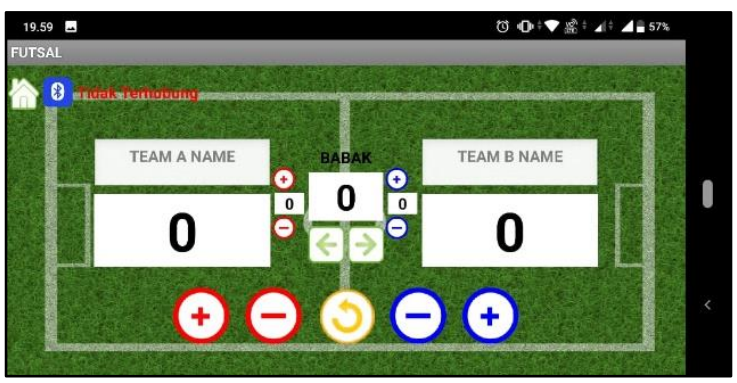

Gambar 11. Tampilan Menu Futsal Score Board

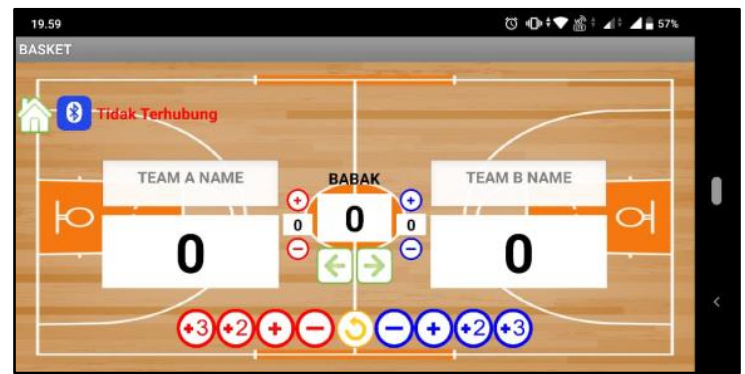

Gambar 12. Tampilan Menu Basket Score Board 


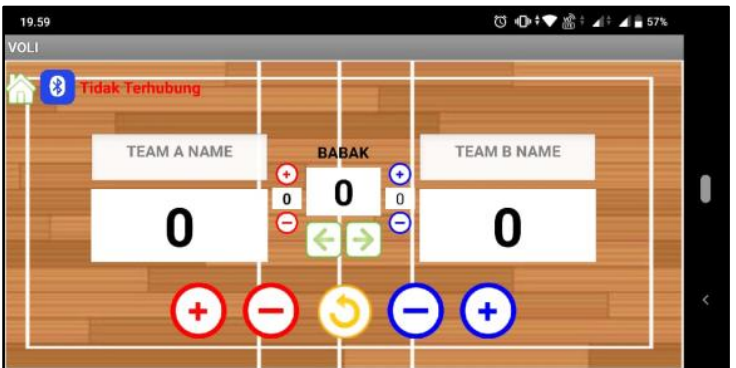

Gambar 13. Tampilan Menu Voli dan Bulu Tangkis

\section{Hasil Pengujian}

Tabel 2. Hasil Pengujian Bluetooth Tanpa Penghalang

\begin{tabular}{lccc}
\hline No & Jarak & $\begin{array}{c}\text { Status } \\
\text { Koneksi }\end{array}$ & $\begin{array}{c}\text { Waktu } \\
\text { Koneksi }\end{array}$ \\
\hline 1 & 1 meter & Terhubung & 1 detik \\
2 & 2 meter & Terhubung & 1,5 detik \\
3 & 3 meter & Terhubung & 2 detik \\
4 & 4 meter & Terhubung & 2 detik \\
5 & 5 meter & Terhubung & 2,5 detik \\
6 & 6 meter & Terhubung & 3 detik \\
7 & 7 meter & Terhubung & 3,2 detik \\
8 & 8 meter & Terhubung & 3,2 detik \\
9 & 9 meter & Terhubung & 3,2 detik \\
10 & 10 meter & Terhubung & 3,4 detik \\
\hline
\end{tabular}

Tabel 3. Hasil Pengujian Bluetooth Dengan

\begin{tabular}{cccc}
\multicolumn{3}{c}{ Penghalang } \\
\hline No & Jarak & $\begin{array}{c}\text { Status } \\
\text { Koneksi }\end{array}$ & $\begin{array}{c}\text { Waktu } \\
\text { Koneksi }\end{array}$ \\
\hline 1 & 1 meter & Terhubung & 1 detik \\
2 & 2 meter & Terhubung & 1,5 detik \\
3 & 3 meter & Terhubung & 2 detik \\
4 & 4 meter & Terhubung & 2 detik \\
5 & 5 meter & Terhubung & 3,5 detik \\
6 & 6 meter & Terhubung & 3,5 detik \\
7 & 7 meter & Terhubung & 3,7 detik \\
8 & 8 meter & Terhubung & 3,7 detik \\
9 & 9 meter & Terhubung & 3,8 detik \\
10 & 10 meter & Terhubung & 3,8 detik \\
\hline
\end{tabular}

Tabel 4. Hasil Pengujian Menu Futsal

\begin{tabular}{ccccc}
\hline No & Fitur & Pengujian & Status & $\begin{array}{c}\text { Tampil } \\
\text { Ke LED }\end{array}$ \\
\hline 1 & Bluetooth & $\begin{array}{c}\text { Apakah bisa } \\
\text { melakukan } \\
\text { pairing } \\
\text { bluetooth }\end{array}$ & Berhasil & $\begin{array}{c}\text { Tidak } \\
\text { Tampil }\end{array}$ \\
\hline
\end{tabular}

\begin{tabular}{|c|c|c|c|c|}
\hline 2 & $\begin{array}{l}\text { Tombol } \\
\text { Tambah } \\
\text { Skor }\end{array}$ & $\begin{array}{l}\text { Apakah bisa } \\
\text { menambah skor }\end{array}$ & Berhasil & Tampil \\
\hline 3 & $\begin{array}{l}\text { Tombol } \\
\text { Kurang } \\
\text { Skor }\end{array}$ & $\begin{array}{l}\text { Apakah bisa } \\
\text { mengurangi } \\
\text { skor }\end{array}$ & Berhasil & Tampil \\
\hline 4 & $\begin{array}{l}\text { Tombol } \\
\text { Tambah } \\
\text { Pelangga } \\
\text { ran }\end{array}$ & $\begin{array}{l}\text { Apakah bisa } \\
\text { menambah } \\
\text { pelanggaran }\end{array}$ & Berhasil & $\begin{array}{l}\text { Tidak } \\
\text { Tampil }\end{array}$ \\
\hline 5 & $\begin{array}{c}\text { Tombol } \\
\text { Kurang } \\
\text { Pelangga } \\
\text { ran }\end{array}$ & $\begin{array}{l}\text { Apakah bisa } \\
\text { mengurangi } \\
\text { pelanggaran }\end{array}$ & Berhasil & $\begin{array}{c}\text { Tidak } \\
\text { Tampil }\end{array}$ \\
\hline 6 & $\begin{array}{l}\text { Tombol } \\
\text { Tambah } \\
\text { Babak }\end{array}$ & $\begin{array}{l}\text { Apakah bisa } \\
\text { menambah } \\
\text { babak }\end{array}$ & Berhasil & Tampil \\
\hline 7 & $\begin{array}{l}\text { Tombol } \\
\text { Kurang } \\
\text { Babak }\end{array}$ & $\begin{array}{c}\text { Apakah bisa } \\
\text { mengurangi } \\
\text { babak }\end{array}$ & Berhasil & Tampil \\
\hline 8 & $\begin{array}{l}\text { Tombol } \\
\text { Reset } \\
\text { Keseluru } \\
\text { han }\end{array}$ & $\begin{array}{c}\text { Apakah bisa } \\
\text { mereset ulang } \\
\text { skor, babak dan } \\
\text { pelanggaran }\end{array}$ & Berhasil & Tampil \\
\hline 9 & Home & $\begin{array}{l}\text { Apakah bisa } \\
\text { kembali ke } \\
\text { menu utama }\end{array}$ & Berhasil & $\begin{array}{c}\text { Tidak } \\
\text { Tampil }\end{array}$ \\
\hline
\end{tabular}

Tabel 5. Hasil Pengujian Menu Basket

\begin{tabular}{|c|c|c|c|c|}
\hline No & Fitur & Pengujian & Status & $\begin{array}{r}\text { Tampil } \\
\text { Ke LED }\end{array}$ \\
\hline 1 & Bluetooth & $\begin{array}{l}\text { Apakah bisa } \\
\text { melakukan } \\
\text { pairing } \\
\text { bluetooth }\end{array}$ & Berhasil & $\begin{array}{c}\text { Tidak } \\
\text { Tampil }\end{array}$ \\
\hline 2 & $\begin{array}{l}\text { Tombol } \\
\text { Tambah } \\
\text { Skor }\end{array}$ & $\begin{array}{l}\text { Apakah bisa } \\
\text { menambah } \\
\text { skor }\end{array}$ & Berhasil & Tampil \\
\hline 3 & $\begin{array}{l}\text { Tombol } \\
\text { Kurang } \\
\text { Skor }\end{array}$ & $\begin{array}{l}\text { Apakah bisa } \\
\text { mengurangi } \\
\text { skor }\end{array}$ & Berhasil & Tampil \\
\hline 4 & $\begin{array}{l}\text { Tombol } \\
\text { Tambah } \\
\text { Ronde } \\
\text { Menang }\end{array}$ & $\begin{array}{c}\text { Apakah bisa } \\
\text { menambah } \\
\text { ronde menang }\end{array}$ & Berhasil & $\begin{array}{l}\text { Tidak } \\
\text { Tampil }\end{array}$ \\
\hline 5 & $\begin{array}{l}\text { Tombol } \\
\text { Kurang } \\
\text { Ronde } \\
\text { Menang }\end{array}$ & $\begin{array}{c}\text { Apakah bisa } \\
\text { mengurangi } \\
\text { monde menang }\end{array}$ & Berhasil & $\begin{array}{c}\text { Tidak } \\
\text { Tampil }\end{array}$ \\
\hline 6 & $\begin{array}{l}\text { Tombol } \\
\text { Tambah } \\
\text { Babak }\end{array}$ & $\begin{array}{c}\text { Apakah bisa } \\
\text { menambah } \\
\text { babak }\end{array}$ & Berhasil & Tampil \\
\hline 7 & $\begin{array}{l}\text { Tombol } \\
\text { Kurang } \\
\text { Babak }\end{array}$ & $\begin{array}{c}\text { Apakah bisa } \\
\text { mengurangi } \\
\text { babak }\end{array}$ & Berhasil & Tampil \\
\hline 8 & $\begin{array}{l}\text { Tombol } \\
\text { Reset } \\
\text { Keseluru } \\
\text { han }\end{array}$ & $\begin{array}{l}\text { Apakah bisa } \\
\text { mereset ulang } \\
\text { skor, babak } \\
\text { dan ronde } \\
\text { menang }\end{array}$ & Berhasil & Tampil \\
\hline
\end{tabular}




\begin{tabular}{lllc}
\hline Home & $\begin{array}{c}\text { Apakah bisa } \\
\text { kembali ke } \\
\text { menu utama }\end{array}$ & Berhasil & $\begin{array}{c}\text { Tidak } \\
\text { Tampil }\end{array}$ \\
\hline
\end{tabular}

Tabel 6. Hasil Pengujian Menu Voli

\begin{tabular}{|c|c|c|c|c|}
\hline No & Fitur & Pengujian & Status & $\begin{array}{l}\text { Tampil } \\
\text { Ke LED }\end{array}$ \\
\hline 1 & Bluetooth & $\begin{array}{l}\text { Apakah bisa } \\
\text { melakukan } \\
\text { pairing } \\
\text { bluetooth }\end{array}$ & Berhasil & $\begin{array}{c}\text { Tidak } \\
\text { Tampil }\end{array}$ \\
\hline 2 & $\begin{array}{l}\text { Tombol } \\
\text { Tambah } \\
\text { Skor }\end{array}$ & $\begin{array}{c}\text { Apakah bisa } \\
\text { menambah skor }\end{array}$ & Berhasil & Tampil \\
\hline 3 & $\begin{array}{l}\text { Tombol } \\
\text { Tambah } \\
\text { Skor }+2 \\
\text { Tombol }\end{array}$ & $\begin{array}{c}\text { Apakah bisa } \\
\text { menambah skor } \\
\text { dengan nilai +2 } \\
\text { Apakah bisa }\end{array}$ & B & Tampil \\
\hline 4 & $\begin{array}{l}\text { Tambah } \\
\text { Skor }+3\end{array}$ & $\begin{array}{l}\text { menambah skor } \\
\text { dengan nilai }+3\end{array}$ & Berhasil & Tampil \\
\hline 5 & $\begin{array}{l}\text { Tombol } \\
\text { Kurang } \\
\text { Skor }\end{array}$ & $\begin{array}{l}\text { Apakah bisa } \\
\text { mengurangi } \\
\text { skor }\end{array}$ & Berhasil & Tampil \\
\hline 6 & $\begin{array}{l}\text { Tombol } \\
\text { Tambah } \\
\text { Pelangga } \\
\text { ran }\end{array}$ & $\begin{array}{l}\text { Apakah bisa } \\
\text { menambah } \\
\text { pelanggaran }\end{array}$ & Berhasil & $\begin{array}{l}\text { Tidak } \\
\text { Tampil }\end{array}$ \\
\hline 7 & $\begin{array}{l}\text { Tombol } \\
\text { Kurang } \\
\text { Pelangga } \\
\text { ran }\end{array}$ & $\begin{array}{l}\text { Apakah bisa } \\
\text { mengurangi } \\
\text { pelanggaran }\end{array}$ & Berhasil & $\begin{array}{l}\text { Tidak } \\
\text { Tampil }\end{array}$ \\
\hline 8 & $\begin{array}{l}\text { Tombol } \\
\text { Tambah } \\
\text { Babak }\end{array}$ & $\begin{array}{l}\text { Apakah bisa } \\
\text { menambah } \\
\text { babak }\end{array}$ & asil & Tampil \\
\hline 9 & $\begin{array}{l}\text { Tombol } \\
\text { Kurang } \\
\text { Babak }\end{array}$ & $\begin{array}{l}\text { Apakah bisa } \\
\text { mengurangi } \\
\text { babak }\end{array}$ & Berhasil & Tampil \\
\hline 10 & $\begin{array}{l}\text { Tombol } \\
\text { Reset } \\
\text { Keseluru } \\
\text { han }\end{array}$ & $\begin{array}{c}\text { Apakah bisa } \\
\text { mereset ulang } \\
\text { skor, babak dan } \\
\text { pelanggaran }\end{array}$ & Berhasil & Tampil \\
\hline 11 & Home & $\begin{array}{l}\text { Apakah bisa } \\
\text { kembali ke } \\
\text { menu utama }\end{array}$ & Berhasil & $\begin{array}{c}\text { Tidak } \\
\text { Tampil }\end{array}$ \\
\hline
\end{tabular}

Tabel 7. Hasil Pengujian Menu Bulu Tangkis

\begin{tabular}{|c|c|c|c|c|}
\hline No & Fitur & Pengujian & Status & $\begin{array}{r}\text { Tampil } \\
\text { Ke LED }\end{array}$ \\
\hline 1 & Bluetooth & $\begin{array}{c}\text { Apakah bisa } \\
\text { melakukan } \\
\text { pairing } \\
\text { bluetooth }\end{array}$ & Berhasil & $\begin{array}{c}\text { Tidak } \\
\text { Tampil }\end{array}$ \\
\hline 2 & $\begin{array}{l}\text { Tombol } \\
\text { Tambah } \\
\text { Skor }\end{array}$ & $\begin{array}{c}\text { Apakah bisa } \\
\text { menambah } \\
\text { skor }\end{array}$ & Berhasil & Tampil \\
\hline 3 & $\begin{array}{c}\text { Tombol } \\
\text { Kurang } \\
\text { Skor }\end{array}$ & $\begin{array}{c}\text { Apakah bisa } \\
\text { mengurangi } \\
\text { skor }\end{array}$ & Berhasil & Tampil \\
\hline
\end{tabular}

\begin{tabular}{|c|c|c|c|c|}
\hline 4 & $\begin{array}{l}\text { Tombol } \\
\text { Tambah } \\
\text { Ronde } \\
\text { Menang }\end{array}$ & $\begin{array}{l}\text { Apakah bisa } \\
\text { menambah } \\
\text { ronde menang }\end{array}$ & Berhasil & $\begin{array}{c}\text { Tidak } \\
\text { Tampil }\end{array}$ \\
\hline 5 & $\begin{array}{l}\text { Tombol } \\
\text { Kurang } \\
\text { Ronde } \\
\text { Menang }\end{array}$ & $\begin{array}{c}\text { Apakah bisa } \\
\text { mengurangi } \\
\text { monde menang }\end{array}$ & Berhasil & $\begin{array}{c}\text { Tidak } \\
\text { Tampil }\end{array}$ \\
\hline 6 & $\begin{array}{l}\text { Tombol } \\
\text { Tambah } \\
\text { Babak }\end{array}$ & $\begin{array}{l}\text { Apakah bisa } \\
\text { menambah } \\
\text { babak }\end{array}$ & Berhasil & Tampil \\
\hline 7 & $\begin{array}{l}\text { Tombol } \\
\text { Kurang } \\
\text { Babak }\end{array}$ & $\begin{array}{l}\text { Apakah bisa } \\
\text { mengurangi } \\
\text { babak }\end{array}$ & Berhasil & Tampil \\
\hline 8 & $\begin{array}{l}\text { Tombol } \\
\text { Reset } \\
\text { Keseluru } \\
\text { han }\end{array}$ & $\begin{array}{l}\text { Apakah bisa } \\
\text { mereset ulang } \\
\text { skor, babak } \\
\text { dan ronde } \\
\text { menang }\end{array}$ & Berhasil & Tampil \\
\hline 9 & Home & $\begin{array}{l}\text { Apakah bisa } \\
\text { kembali ke } \\
\text { menu utama }\end{array}$ & Berhasil & $\begin{array}{c}\text { Tidak } \\
\text { Tampil }\end{array}$ \\
\hline
\end{tabular}

\section{Kesimpulan}

1. Sistem aplikasi score board dirancang menggunakan beberapa alat dan bahan yaitu Arduino Uno sebagai mikrokontroler, bluetooth HC 05 merupakan alat penghubung antara sistem kendali dan smartphone, modul p10 led matrix sebagai tampilan layar skor, power supply sebagai pengatur tegangan listrik, kabel jumper dan smartphone sebagai kendali skor. Sistem aplikasi score board dibuat dengan merangkai seluruh komponen alat dengan kabel jumper dan dmd konektor sebagai penghubung antar komponen.

2. Sistem memiliki 4 cabang pertandingan olahraga yaitu pertandingan futsal, basket, voli dan bulu tangkis. Dalam perancangan aplikasi smartphone, perintah yang di input dalam app inventor harus sesuai dengan program yang diupload dirangkaian sistem kendali. Apabila perintah yang diupload dalam rangkaian tidak sesuai dengan perintah yang diinput di aplikasi smartphone, maka aplikasi smartphone yang dirancang tidak berfungsi.

3. Sistem aplikasi pada penelitian ini menggunakan perangkat bluetooth untuk koneksinya yang dapat digunakan pada radius kurang lebih 10 meter.

Saran untuk pengembangan aplikasi ini agar memiliki system pengaturan waktu yang real time agar pemain dan penonton dapat mengetahui waktu yang sedang berjalan pada saat pertandingan di mulai dan juga agar meminimalkan adanya kecurangan dari pihak yang tidak bertanggung jawab pada pertandingan yang sedang berjalan. 
Alat ini belum menggunakan tegangan sementara (baterai), apabila terjadi mati listrik maka skor pada pertandingan tersebut akan hilang.

\section{Daftar Pustaka}

[1]. Marti W.S., Hafid H. 2016. Implementasi Aplikasi Monitoring Untuk Pengendalian Pintu Gerbang Rumah Dengan Menggunakan APP Invertor Berbasis Android. Jurnal EKSIS Mei 2016: halaman $20-28$.

[2]. Hendro W.S., Rafael S.W., 2015. Penggunaan APP Invertor Dalam Pembuatan Game Education berbasi Android Sebagai Media Pembelajaran., Universitas Negri Semarang.

[3]. Presman, Roger, 2012. Rekayasa Perangkat Lunak Edisi 7. Yogyakarta: andi.

[4]. Jogjarobotika, 2018. Modul led matrix / Running text p10. [Online] Available at: www.jogjarobotika.com [Accessed 2019].

[5]. Massachusetts Institute of Technology, n.d. 2017. MIT App Inventor Explore MIT. [Online] Available at: http://appinventor.mit.edu/ [Accessed 2019].

[6]. Djuandi, F., 2011. Pengenalan Arduino. [Online] Available at: www.Tobku.com [Accessed 2019].

[7]. Arduino, n.d. Arduino-Software. [Online] Available at: www.arduino.cc [Accessed 2019]. 